\title{
Provocation test with $5 \%$ glycerol has fast and fleeting effects on the nasal mucosa
}

\author{
Teste de provocação com glicerol 5\%: efeito rápido e fugaz na mucosa nasal
}

Francisco de Assis Machado Vieira ${ }^{1}$

\section{ABSTRACT}

The effects observed with nasal provocation testing using 5\% glycerol were associated only with irritation/burning sensation within the first few minutes, reducing spontaneously and disappearing quickly. The use of $5 \%$ glycerol was found to have no influence on the prevalence of nasal obstruction, rhinorrhea, sneezing and nasal/ocular itching obtained through summing symptoms, as evaluated in different nasal provocation tests, after 15-20 minutes. Overall, dilution with 5\% glycerol did not change the final score for symptoms during nasal provocation testing.

Keywords: Allergy and immunology, test approval for diagnosis, diagnostic techniques and procedures.

Specific nasal provocation testing (NPT) induces responses from the nasal mucosa by controlling exposure to specific allergens. It is indicated for diagnostic confirmation of allergic rhinitis when discrepancies arise from the assessment of patient's medical history and results of skin and/or serological tests ${ }^{1}$.

SNPT using a lyophilized allergen extract may be diluted the same day as tested, in order to maintain equivalent power between batches. When diluted in aqueous solution, it gradually loses potency, but this can be delayed, though not prevented, by the use
RESUMO

Os efeitos observados com glicerol a 5\% na provocação nasal foram associados unicamente a irritação e sensação de prurido nos primeiros minutos, cedendo espontaneamente e desaparecendo rapidamente. O uso de glicerol a 5\% não influenciou a prevalência de obstrução nasal, rinorreia, espirros e prurido nasal e ocular obtidos na soma dos sintomas, quando avaliado em diferentes testes de provocação nasal específica, após 15-20 minutos. Tomada em conjunto, essa diluição com glicerol a 5\% não altera a pontuação final dos sintomas durante a provocação nasal.

Descritores: Alergia e imunologia, aprovação de teste para diagnóstico, técnicas e procedimentos diagnósticos.

of preservatives. Human serum albumin at $0.03 \%$ is effective as a stabilizer, without being irritating. Meanwhile, $50 \%$ glycerol is more effective than albumin to prevent loss of potency and has been used in all extracts stored for skin prick tests, being kept under refrigeration $\left(2-8^{\circ} \mathrm{C}\right)$ when not in use ${ }^{2}$.

NPT with glycerol solution at $50 \%$ and $5 \%$ may cause nonspecific reactions in the nasal mucosa, as shown in hospitalized patients with asthma associated with rhinitis, ranging from $62 \%$ to $14.7 \%$ respectively, after 15 minutes of application. Glycerol should therefore not be used in allergen extracts

1. Specialist Allergy and Clinical Immunology, Medical - Caxias do Sul, RS, Brazil.

Submitted 29 June 2018; accepted 31 August 2018.

Arq Asma Alerg Imunol. 2018;2(3):379-81.

http://dx.doi.org/10.5935/2526-5393.20180046 
which are meant for challenge tests ${ }^{3}$. It is assumed that patients with rhinitis and asthma has higher total airway hyperreactivity due to comorbid conditions. A link between allergic rhinitis and asthma is evident from epidemiological, pathophysiological and clinical studies ${ }^{4}$.

The dose to start NPT can be calculated based on the results obtained by a skin prick test using allergen extracts; however, it may vary in different protocols. Some authors propose to use a specific concentration able to produce a wheal of $3 \mathrm{~mm}$ or $1: 100 \mathrm{vol} / \mathrm{vol}$ of the extract concentration. NPT with biologically standard allergen may be initiated at a concentration of $1: 1000 \mathrm{vol} / \mathrm{vol}(0.05 \%$ glycerol $)$ and increased ten times successively ${ }^{5}$. While some centers prefer to use a single dose of an allergen, titration has also been commonly used ${ }^{6}$.

Nasal allergen challenge results in increases in lower airway reactivity within 30 minutes, suggesting a neural reflex ${ }^{4}$. In asthmatics, a concentration of 1:10 $\mathrm{vol} / \mathrm{vol}$, with final extract concentration of $5 \%$ glycerol under refrigeration $\left(2-8^{\circ} \mathrm{C}\right)$, could be used carefully. The potency of concentrated immunotherapy extracts (1:1 vol/vol up to $1: 10 \mathrm{vol} / \mathrm{vol})$, when kept at $4^{\circ} \mathrm{C}$, is relatively constant until the expiration date shown on the original label ${ }^{7}$. Dilution with $5 \%$ glycerol, however, could change the final score for the symptoms of NPT.

To test this hypothesis, we selected 140 outpatients, being 69 with rhinitis or rhinoconjunctivitis based on clinical history, associated with positive skin prick tests for one or more house dust mites and/or grass pollens including Lolium multiflorum. Patients with bronchial asthma were excluded. The control group included 71 non-atopic subjects without the features of the previous group. We used a double-blind placebo controlled design. All patients or their guardians received and signed an informed consent form. A 7-day washout period for the use of antihistamines, intranasal corticosteroids or other agents that could interfere with the results was applied.

The solutions tested contained $0.9 \%$ sodium chloride, $0.45 \%$ phenol, and $\mathrm{pH} 5.50$, with or without $5 \%$ glycerol. Samples were prepared in the laboratory by a pharmacist, respectively marked with specific codes in order to mask its contents and kept refrigerated $\left(2-6^{\circ} \mathrm{C}\right)$. Samples were only identified at the end of the study for the statistical analysis.

NPT consisted of spraying $0.2 \mathrm{~mL}$ on a free nasal fossa without anatomical obstruction or mucus, which was confirmed by rhinoscopy. It was directed to the inferior turbinate, separated by a short break, with a slight compression of the site, to avoid possible reflux. The patient held and maintained a deep breath to keep the solution away from the oropharynx. The solution was held in one nostril, keeping the other one as control, including a possible reflex activity. Interchangeable nebulizer devices in contact with the mucosa were individualized and autoclaved. The nasal spray was preferred because it is able to reach the inferior turbinate with high deposition without causing local irritation ${ }^{8}$.

Symptoms were observed in the period between 3-5 minutes and after 15-20 minutes, including irritation/burning sensation, nasal obstruction, itching, sneezing, runny nose, pharynx/palatal irritation and eye itching. The results, including demographic and clinical characteristics, are shown in Table 1. The main symptom (considered positive) consisted of mild irritation/burning sensation in the unilateral nasal cavity, which spontaneously reduced after about 3 minutes and was not observed anymore after 1520 minutes. Positive NPT in atopic and non-atopic patients was, respectively, 4 (5.8\%) and $12(16.9 \%)$ with placebo and $13(18.8 \%)$ and $6(8.4 \%)$ with $5 \%$ glycerol.

Interestingly, $4(2.8 \%)$ of patients showed nasal obstruction using $0.9 \%$ sodium chloride solution early in the test and maintained later; however, it did not coincide with the use of either placebo or $5 \%$ glycerol. To calculate the statistical significance of placebo versus $5 \%$ glycerol, the chi-square test was used, with $P$-value $<0.05$. Concentrated solutions with antigens $1: 1$ used in the skin prick test contain $50 \%$ glycerol, and should not be used undiluted in the NPT, in view of the increased risk of inespecific irritant reactions.

The effects observed with $5 \%$ glycerol in NPT were associated only with irritation/burning sensation within the first few minutes, reducing spontaneously and disappearing quickly. The use of $5 \%$ glycerol was found to have no influence on the prevalence of nasal obstruction, rhinorrhea, sneezing and nasal/ocular itching, obtained through summing the symptoms, when evaluated in different NPTs, after 15-20 minutes.

Overall, the dilution with $5 \%$ glycerol did not change the final score for the symptoms of NPT and may have a relevant clinical applicability when using provocation tests. 


\section{Table 1}

Patients' demographic and clinical data

$\begin{array}{ll}\text { Feature } & \text { Atopic and non-atopic }(n=140)\end{array}$

Sex M/F, n (\%)

Groups: adults/children, (\%)

Age range, $y$

Atopic rhinitis and/or rhinoconjunctivitis, $\mathrm{n}(\%)$

Non-atopic, n (\%)

Positive NPT (placebo), atopic/non-atopic, n (\%)

Positive NPT (5\% glycerol), atopic/non-atopic, n (\%)*

OS (placebo), n (\%)

OS (5\% glycerol), n (\%)
88 (62.9) / 52 (37.1)

131 (93.6) / 9 (6.4)

$13-60$

69 (49.3)

$71(50.7)$

$4(5.8) / 12(16.9)$

13 (18.8) / 6 (8.4), p < 0.05

2 (1.4)

$2(1.4)$

NPT = nasal provocation test; OS = other symptoms.

${ }^{*}$ Chi-square test.

\section{References}

1. Dordal MT, Lluch-Bernal M, Sánchez MC, Rondón C, Navarro A, Montoro J, etal. Allergen-specific nasal provocation testing: review by rhinoconjuntivitis comitee of Spanish Society of Allergy and Clinical Immunology. J Investig Allergol Clin Immunol. 2011;21(1):1-12.

2. Nelson HS. Effect of preservative and conditions of storage on the potency of allergy extracts. J Allergy Clin Immunol. 1981;67:64-7.

3. HaahtelaT, Lahdensuo A. Non-specific reactions caused by diluents containing glycerol in nasal and bronchial challenge tests. Clin Allergy. 1979;9:225-7.

4. Corren J. Allergic rhinitis and asthma: how important is the link? J Allergy Clinical Immunol. 1997;99:781-6.

5. Solomon WR. Nasal provocation testing. In: Spector SL, ed. Provocation testing in clinical practice. Vol. 5. New York: Marcel Dekker; 1995. p. 647-92.

6. Baumann R, Rabaszowski M, Stenin I, Gaertner-Akerboom M, Scheckenbach K, Wiltfang J, et al. The release of IL-31 and IL 13 after nasal allergen challenge and their relation to nasal symptoms. Clin Transl Allergy. 2012;2:13.
7. Cox L, James T, Lockey R, Nelson H, Lockey R. Allergen immunotherapy: a practice parameter second update. J Allergy Clin Immunol. 2007;120:S25-S85.

8. Foo MY, Cheng Y, Su W, Donovan MD. The influence of spray properties on intranasal deposition. J Aerosol Med. 2007;20(4):495-508.

No conflicts of interest declared concerning the publication of this article.

Correspondence:

Francisco de Assis Machado Vieira

E-mail: famvieira@ hotmail.com 